\title{
AMINO-ACIDURIA AND HYPERMETABOLISM IN PROGERIA
}

\author{
BY
}

\author{
A. HARELl STEINBERG, A. SZEINBERG and B. E. COHEN \\ From Tel Hashomer Government Hospital, Israel
}

(RECEIVED FOR PUBLICATION APRIL 9, 1957)

In 1886 Hutchinson described the first case of alopecia totalis congenita associated with atrophy of the skin, and in 1904 Gilford reported a similar case and described it as premature senility (senilitas praecox) or progeria. From that time to the present about 20 cases have been described in the world literature (Curtin and Kotzen, 1929; Talbot, Butler, Pratt, MacLachlan and Tannheimer, 1945; Plunkett, Sawtelle and Hamblen, 1954).

Up to the present time the diagnosis has been based, in the absence of any constant biochemical findings, upon the strange external appearance which is constant and recurs in all these cases. We are presenting the following case mainly because several results were obtained during the clinical and laboratory investigations that could be used to explain some of the features of this illness.

\section{Case Report}

The patient was a boy of $5 \frac{1}{2}$ years, born of parents from Rumania. Both parents were healthy and unrelated. The child was born several months after the parents arrived in Israel. Until the age of about 8 months he developed normally, gained weight satisfactorily and showed no signs of any ailment. He sat up at the age of 7 months and walked at the age of 11 months. His mental development was also within normal limits. $\mathrm{He}$ began to talk at the age of 13 months and was a bright, pleasant infant, playing with his parents and the children of their neighbours.

The only thing that appeared somewhat strange to the parents was the absence of hair, a somewhat large head, and perhaps the fact that his first tooth was rather delayed, appearing only at the age of 10 months. At this time the signs of his present illness began to appear: he ceased to gain in weight, the few hairs that he had fell out, his round infantile features became thinner and sharper, and the whole of his head became bird-like.

After several consultations his illness was diagnosed as progeria and numerous therapeutic experiments were without avail: he received vitamins, calcium and even D.O.C.A. for several weeks without any effect. When he was treated with A.C.T.H., however, he gained $2 \frac{1}{2} \mathrm{~kg}$. in weight and also grew $2 \mathrm{~cm}$. in height; but even these effects were temporary, if indeed we can attribute the slight gain in height and weight to this drug. Eventually, he was sent for consultation to a neurosurgeon* and we were requested by him to take part in the metabolic and endocrinological investigations of the patient.

When he was admitted to hospital he weighed $9.680 \mathrm{~kg}$. His appearance was typical of 'classical' progeria. His nose was sharp and bent, and the bones of the cheeks and chin were small compared with the bones of the forehead. His height was $90 \mathrm{~cm}$. His body build was symmetrical although dwarfed and the skin was thin, partisularly on the head, with prominence of the venous pattern. On the body the skin was dry with a faint golden-brown pigmentation in small spots. He had no hair at all; the head was relatively large with prominent eyes partly due to shallow orbital fossae and partly to actual exophthalmos. His teeth were very bad. Fundi and perimetry were normal. No cataracts were noted, and we were unable to feel the thyroid gland with certainty. The chest was narrow but the heart and lungs were within normal limits. The abdomen was protuberant but we were unable to feel the liver or the spleen. The genitals were perhaps slightly larger than the normal for his age and the testicles were in the normal position. The limbs were without pathological findings except for mild flat feet and small and narrow nails. The muscles were weak and poorly developed. The reflexes were normal and he had an unusually high and nasal voice. The E.C.G., E.E.G. and radiographs were all normal.

Intelligence testing was done. The child was lively and able to orientate himself accurately. He took part in conversation and seemed to prefer the company of adults, although the operative intelligence appeared limited in several directions and functions.

Laboratory Investigation. There were two groups of abnormal findings: (1) the excretion of amino-acids and (2) increased metabolic activity.

The amino-acids concentrations were low in the blood (4.8 mg. \% as against a normal finding of 6 to $8 \mathrm{mg}$. \%) and increased in the urine.

The amino-acid excretion in the urine was examined by ascending paper chromatography. One-dimensional

* The examination was carried out by Dr. Askenasy at the Beilinson Hospital and we are indebted to him for his courtesy in transferring the child to us. 
chromatography was carried out in a butanol : acetic acid: water (11:3:4) solvent, two-dimensional examinations were developed in 3 parts isopropanol: $1 \%$ sodium chloride solution containing 1 part $0.5 \%$ urea and $80 \%$ phenol solution containing $0.1 \% 8$ hydroxyquinoline.

Several examinations were carried out (testing always a 1/40,000 part of a 24-hour urine collection) and a marked amino-aciduria was always detected. The pattern of increased excretion was not constant; in some samples a general amino-aciduria was found (glycine, serine, lysine, arginine, alanine, histidine, taurine, threonine) while on other days only one or two acids were excreted in great excess (histidine, or glutamine and lysine).

A semi-quantitative examination was carried out by a method adapted from Smith and Tompsett (1954). A one-dimensional chromatogram of the urine was divided into 10 equal strips corresponding to increasing $R_{t}$

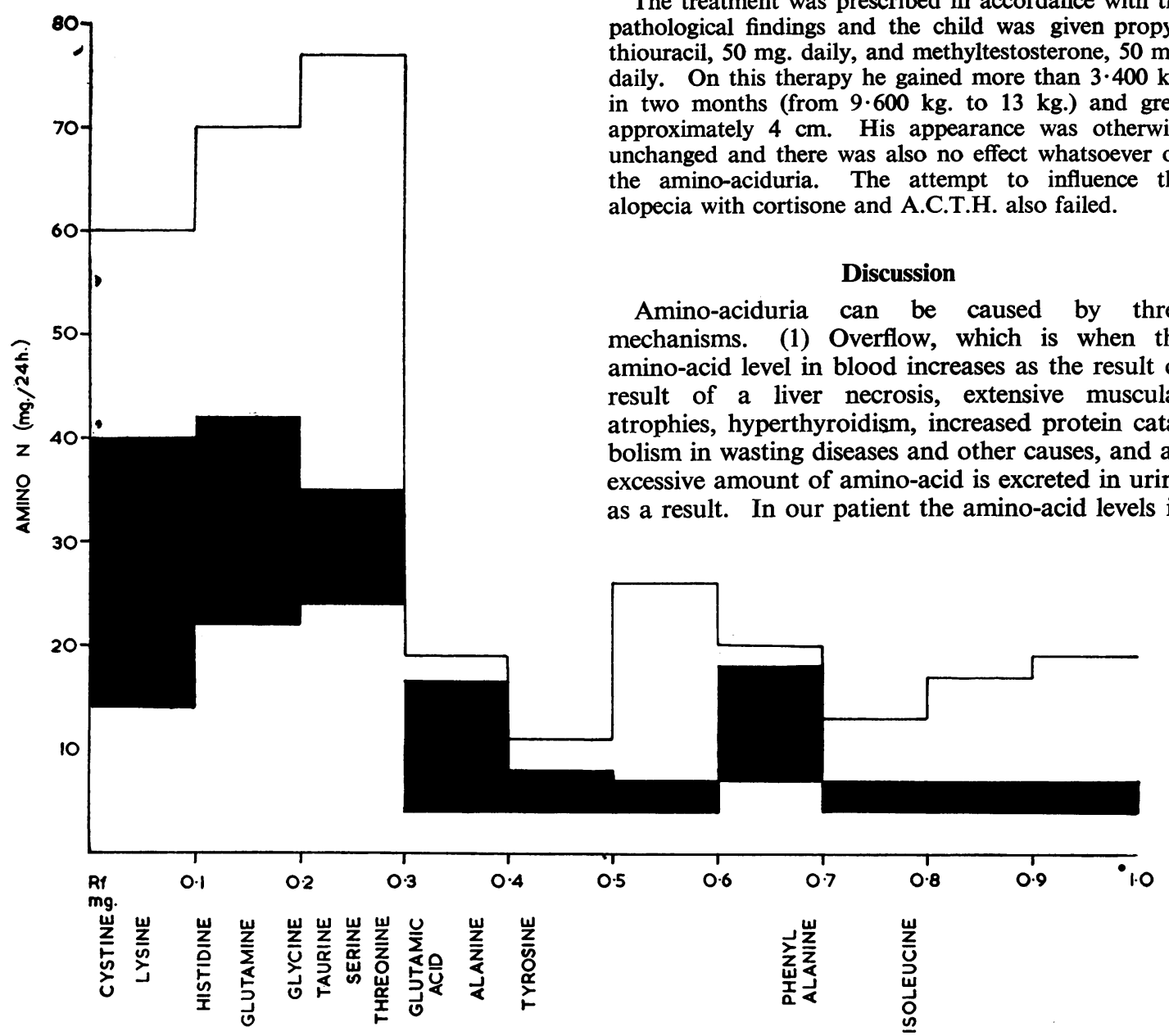

Fig. 1.-Amino-acid excretion in the urine of the patient (the shaded area represents normal excretion).

values. The amino-acids were eluted into a buffered ninhydrin solution and the colours resulting read in a spectrophotometer. The results of the readings were computed from a standard curve prepared with glycine as the reference acid and plotted on graph paper against the corresponding $R_{f}$ values. An example of such an examination of the patient's urine is given in Fig. 1, showing a general amino-aciduria.

The blood amino-acids were examined by the sodiumbeta-naphtoquinone method (Kolmer and Boerner, 1945) and were found to be lowered: whole-blood aminoacids $4.8 \mathrm{mg}$. \% (normal 6-8) and serum-amino-acids $2.9 \mathrm{mg}$. \% (normal 4-6).

In addition to the finding of alterations in the levels of the amino-acids only one other finding was obvious and that was the result of the test with radioactive iodine which showed increased absorption of the iodine by the thyroid gland. This finding was confirmed also by the P.B.I. and B.M.R. (Fig. 2).

The treatment was prescribed in accordance with the pathological findings and the child was given propylthiouracil, $50 \mathrm{mg}$. daily, and methyltestosterone, $50 \mathrm{mg}$. daily. On this therapy he gained more than $3.400 \mathrm{~kg}$. in two months (from $9.600 \mathrm{~kg}$. to $13 \mathrm{~kg}$.) and grew approximately $4 \mathrm{~cm}$. His appearance was otherwise the amino-aciduria. The attempt to influence the alopecia with cortisone and A.C.T.H. also failed.

Amino-aciduria can be caused by three mechanisms. (1) Overflow, which is when the amino-acid level in blood increases as the result of result of a liver necrosis, extensive muscular atrophies, hyperthyroidism, increased protein catabolism in wasting diseases and other causes, and an excessive amount of amino-acid is excreted in urine as a result. In our patient the amino-acid levels in

政


blood never exceeded the normal limits. We were therefore able to exclude overflow as the explanation.

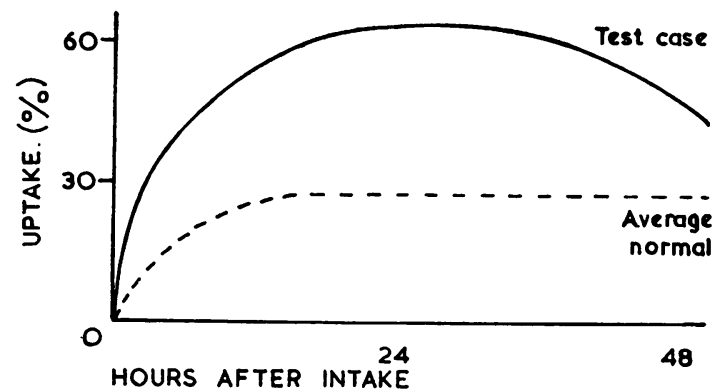

FIG. 2.-Results of thyroid function tests.

(2) Widespread renal damage, in which aminoaciduria is accompanied by other signs of renal disorder, such as haematuria, pyuria, or albuminuria, but none of these signs was found in our patient.

(3) Primary amino-aciduria of the type found in the de Toni-Fanconi syndrome, hepatolenticular degeneration or cystinuria, in which disorders the amino-aciduria is probably caused by specific tubular damage, interfering with normal reabsorption of some substances without giving rise to general

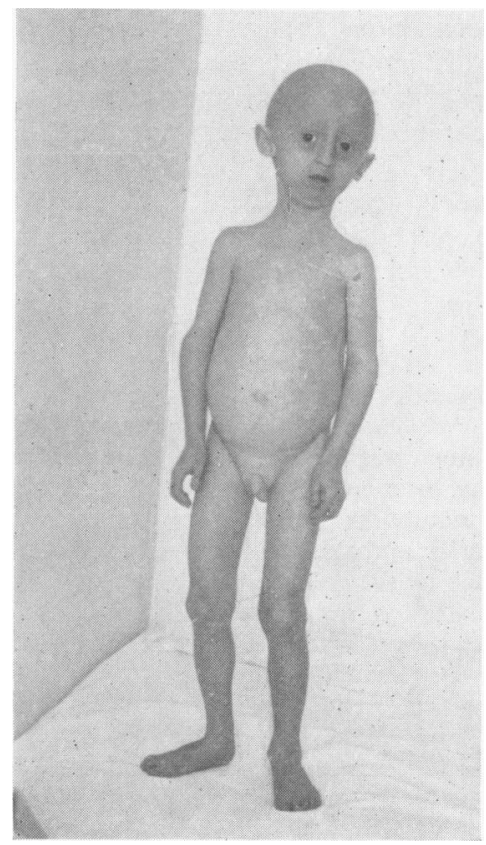

Fig. 3. kidney damage and without any rise of amino-acid concentration in the blood.

The finding of a constant amino-aciduria accompanied by a low blood amino-acid level seems to indicate a defect similar to that of the de ToniFanconi type in our case of progeria.

We also tried to localize the site of hypermetabolism in our case. In general, it is not thought that the thyroid gland plays any part in the pathogenesis of the hypermetabolism in progeria. In our patient the rapid and increased absorption of the radioactive iodine would have suggested that the thyroid gland was over-active, causing the increased metabolism (Talbot et al., 1945).

\section{Summary}

A case of progeria is described in a boy aged $6 \frac{1}{2}$ years. The main biochemical findings were (1) hypoaminoacidaemia, (2) hyperaminoaciduria, (3) increased $I_{131}$ thyroid uptake, (4) high P.B.I. values in blood.

It is suggested that the disease may be related to the de Toni-Fanconi group.

\section{Appendix}

In consultation with Professor Gaillard (Leyden) we tried to ascertain whether there were any constituents that could shorten the life span of the cells in the patient's serum. With the help of the Medical School, Jerusalem, the blood of the patient was examined for haemolysins and leucocytins. These, however, were absent. We were therefore unable to postulate increased destruction of leucocytes or erythrocytes. The leucocytes were kept alive in vitro for 49 hours at a temperature of $6^{\circ} \mathrm{C}$. and they did not differ from normal leucocytes.

We also tested the phagocytosis of the leucocytes of standard Staph. aureus organisms compared with leucocytes of normal blood and no difference was found. Transfer of the patient's leucocytes to normal plasma and also transfer of the child's plasma to normal blood showed no deviation from the normal; the phagocytes developed normally.

\section{REFERENCES}

Curtin, V. T. and Kotzen, H. F. (1929). Amer. J. Dis. Child., 38, 993. Gilford, H. (1904). Practitioner, 73, 188.

Hutchinson, J. (1886). Med.-chir. Trans., 69, 473. As cited in Plunkett et al. (1954).

Kolmer, J. A. and Boerner, F. (1945). Approved Laboratory Technic, 4th ed. New York and London.

Plunkett, E. R., Sawtelle, W. E. and Hamblen, E. C. (1954). J. clin. Endocr., 14, 735.

Smith, D. C. and Tompsett, S. L. (1954). J. clin. Path., 7, 79.

Talbot, N. B., Butler, A. M., Pratt, E. L., MacLachlan, E. A. and Tannheimer, J. (1945). Amer. J. Dis. Child., 69267. 